\title{
Factors of Risk Reduction in Agile and Lean Enabled Governance of IT Project Portfolios
}

\author{
Goran Banjanin \\ Imaging Advice Consultancy \\ Rijeka, Croatia \\ Vjeran Strahonja \\ Faculty of Organization and Informatics \\ Varaždin, Croatia
}

gbanjanin@imaging-advice.com

vjeran.strahonja@foi.hr

\begin{abstract}
The subject of this paper is project portfolio governance and its improvement based on agile and lean methods and concepts. The main objective is to propose a new conceptual governance framework which improves the management of project portfolio processes' execution and reduces the risks of portfolio components' implementation.

The existing project portfolio models and governance processes use traditional principles, regulation, planning, and control methods, which require enhancement to ensure the portfolio management processes are followed in successful project implementation. The agile and lean project portfolio governance is a relative new domain for which the awareness and practical results related to influence on governance processes, risks, and quality are missing.

The contribution is foremost methodological in introduction of agile and lean portfolio governance methods and processes, followed by the agile and lean governance framework, and conclusively in revealing the factors of risk reduction in the agile and lean enabled project portfolio governance with the emphasis on implementation risks reduction.
\end{abstract}

Keywords: Governance, Project Portfolio, Agile, Lean, Reduction of implementation risks.

\section{Introduction}

The term governance comes from the Latin word gubernare meaning "to steer", or provisioning direction, leadership and control. The overall objective of governance is value creation for the organizational stakeholders through resource and risk optimization and benefits realization. Governance is the responsibility of the board of directors, under the leadership of the chairperson [1]. Today's organizational practices recognize organizational, IT, portfolio, program, and project governance structure. Project portfolio governance framework is a discipline within the organizational governance, and its methods and techniques applied within the context of the organizational governance provide reasonable assurance that the organizational strategy can be achieved [2].

Portfolio governance is established by the governing body to make decisions about investments and priorities and ensure the portfolio management processes are followed to sustain the organization [2]. The governing body has the authority to evaluate the portfolio performance and to make resourcing, investment, priority decisions as needed, regular reviews, and analyze the risks and benefits associated with the portfolio components (programs, projects and other work). The governance ensures that the portfolio objectives are achieved by evaluating stakeholder's needs conditions and options, by setting direction through prioritization and decision making, and monitoring performance, compliance and progress against agreed-on directions and objectives. Governance includes two main functions: planning (setting and monitoring mission, strategic plan, principles and ethics, funding, accountability, supervision, and development of policies and statutory compliance) and checking (monitoring and control, ensuring that risks are managed, and performance reviews). 
The motivation for such a research comes from the consideration that the governance processes are essential for the successful project/program implementation, and its improvement shall contribute to that aim [3]. Based author's research, identified project portfolio governance risks can be ascertained in more than $75 \%$ of finalized projects, and the sequence of their adverse impact can be established in more than $50 \%$ of cases.

\section{Methodological framework}

This section presents the research on methodologies and concepts of agile software development and lean manufacturing used in development of the methodological governance framework and its processes, which application improves the governance methods and especially the governance processes and decreases the risks of the project portfolio component performance. The relevancy of such a framework was presented by identification of agile and lean factors impacting project portfolio governance, and further project portfolio risk data analysis. Based on analysis findings, the risk corrective measures are developed to identify, evaluate, and provide the best-fit agile and lean factors to be applied at the different process stages of the project portfolio governance framework.

\subsection{Research overview}

One of the referent researches of the agile governance methods, conducted by Boehm and Turner [4], considers that the agile governance is essential for leveraging and harmonizing the users' requirements and it is one of the key factors at the life-cycle phase of the architectural solution regarding to the exclusion of the critical risks. De O. Luna et al. [5] in their research have proved that the agile governance is relatively new, multidisciplinary area focused on organizational performance, which needs to be intensively researched. Cooke [6] researched the productivity of agile methods and governance, assuming that the governance in case of agile approach is structured around three basic factors: shielding organizations against controlled risks at multiple tiers, reduced costs, and delivery of initial benefits and values for the organization. Dinsmore et al. [7] have explored the organizational project governance and its key components, as well as integrating the strategic processes with portfolio.

Krebs [8] researched the agile project portfolio structure and governance in relation to its influence on project portfolio, liaisons with idea management, stakeholders' management and agile teams. Kaplan and Norton [9] research on organizations dedicated to improving the quality of financial reporting through operative internal controls and governance structure, where the governance is observed from the strategy map point of view. Lamm et al. [10] research was focused on an integrated governance (corporate, operational and IT portfolio/project management). Moore [11] researched the strategic project portfolio management considering that the governance aids to the maximizing ideas as well as the selection and balancing of the portfolio candidates (projects). McMahon [12] performed his research on the model of process improvement and maturity, and its relationship with agile practices. Olson and Desheng $\mathrm{Wu}$ [13] divided governance into three divisions: strategic, managerial and operational, and technical. Paladino [14] explored key principles of corporate performance management with regard to strategic planning and cascading the strategy through governing processes.

Parmenter [15] researched performance measures, and by separating into those impacting governance and those impacting management determines that it has a profound impact on reporting. Rad and Levin [16] research was on models of the project portfolio management, assuming that the difference exists in metrics describing delivery of projects including the metrics of the project's product. Simons [17] analyzed the organizational processes resulting in tensions between value creation and control - managing and measuring value and introducing the four levers of control framework.

The focus of Van Grembergen et al. [18] research was on the influence of the organizational governance of the IT practices on business performance. Kumar [19] explored direct connection of governance to agile methods, e.g. connectivity through the Scrum Communities of Practice 
- CoP, and Scrum of Scrum - SoS in creation of agile governance without compromising agility. Marks [20] researched the area of agile governance, and he is mainly focused on improving governance processes and determining the postulates of enterprise agile governance.

\subsection{Agile and lean methodologies}

While the agile methods encompass constantly evolving processes, interaction and feedback, transforming the project-focused approach into product-focused approach of rolling deployments during the product lifecycle, the main idea behind lean methods is to maximize customer value while minimizing (with the intention to eliminate) waste, meaning creation of more value with fewer resources by focusing on continuous increase of its key processes. The goal is to provide perfect value to the customer through a perfect value creation process that has zero waste [22]. The five lean principles extend the lean methods to the organizational level are [23]: specify value from the perspective of the customer; identify all the steps across the whole value stream; make the value stream flowing continuously (without interruption); make only what is pulled by the customer, or introduce pull systems where continuous flow is possible, and strive for (or manage toward) perfection.

As part of research, the concepts and methods of eight agile software development methods for which it is considered the applicability in project portfolio governance were particularly examined (XP, ASD, DSDM, SCRUM, Crystal, FDD, AM, and ISD), then lean methods focusing on value creation by improving the process execution, elimination of process variation and loses (Six Sigma and Lean Six Sigma), and methods focused on the process quality (TQM, Continuous Improvement-Kaizen, and BPR/BPM). The development activities of the lifecycles of these methods were considered in relation to the Application Lifecycle Management $\left(\mathrm{ALM}^{1}\right)$, with emphasis on the methods' life-cycle processes, and analysis and comparison of their attributes and relation towards the related discipline of project portfolio management and operational IT activities. Agile and lean process factors considered applicable in the project portfolio governance, selected from the cited methods, are shown in Table 1.

\subsection{Agile project portfolio governance framework}

The construct of the agile governance framework is based on the research of governance processes and domains by Hobbs and Miller [24], the structure of the frameworks by Klakegg et al. [25], and the control of the frameworks by Simons [17]. It consists of four process domains which influence the agile project portfolio governance, Front-end, Planning, Monitoring, and Deliverables process domains. The domains are interrelated and integrated through the conjoint risk and change management factors, as depicted in Fig. 1.

Front-end are the processes of shaping the project and/or program and building its legitimacy through decision-making episodes and time [24]. Front-end governance processes include development of feasibility studies and analyses, their justification, influence and negotiation with a broad scale of stakeholders, identification of an endeavor, its adaptation and alignment with organizational factors, and finally its approval. Planning governance processes include elements impacting time (schedule) and costs, culture (administrative, management, competence), accountability and leadership.

\footnotetext{
${ }^{1}$ Forrester Research [21] defines ALM as "the coordination of development lifecycle activities, including requirements, modeling, development, build, and testing, through enforcement of processes that span these activities, management of relationships between development artifacts used or produced by these activities, and reporting on progress of the development effort as a whole".
} 


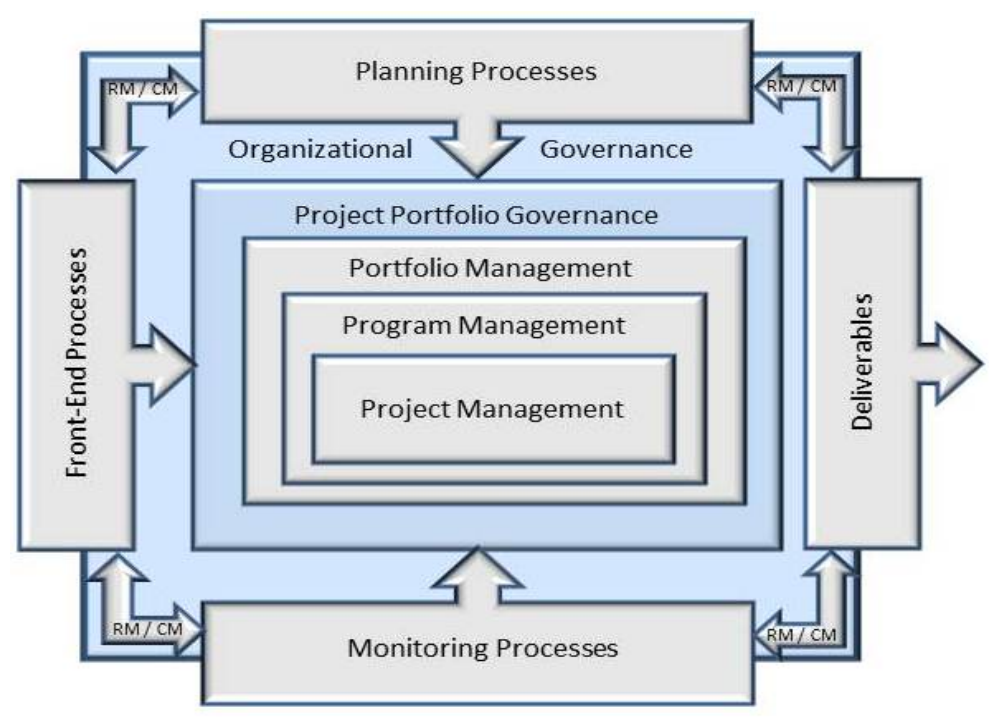

Fig. 1. Agile governance framework construct [based on Hobbs, Miller, Klakegg et. al]

Monitoring governance processes include control framework [17] dealing with the core values of an organization which shall not only be replicated but increased by undertaking a project/program, involved risks, strategic uncertainties, and critical performance variables. Governance processes in the domain of deliverables that influence project/program outcomes include the proper delivery of products or services, adequate performance of investments, authorization of all undertaken work, and the achievement of objectives in required quality.

Table 1. Agile and lean factors impacting the project portfolio governance processes.

\begin{tabular}{|c|c|c|}
\hline \multicolumn{2}{|c|}{ Governance processes } & Agile and lean factors \\
\hline \multirow[t]{5}{*}{ Front-End } & Initiation & Alignment with organizational objectives \\
\hline & Justification & Organizational value creation \\
\hline & Adaptation & Response to change \\
\hline & Alignment & Alignment of business goals \\
\hline & Approval & Decision making \\
\hline \multirow[t]{5}{*}{ Planning } & Strategic planning & Participative alignment \\
\hline & Operational planning supervision & $\begin{array}{l}\text { Real-time planning: plans fully integrated with } \\
\text { project execution }\end{array}$ \\
\hline & $\begin{array}{l}\text { Regulation (set principles, } \\
\text { policies and ethics) }\end{array}$ & $\begin{array}{l}\text { Minimum reasonable set of regulation, standards, } \\
\text { and procedures }\end{array}$ \\
\hline & Accountability identification & Lifecycle traceability \\
\hline & Leadership & $\begin{array}{l}\text { Project management in continuous process } \\
\text { improvement }\end{array}$ \\
\hline \multirow[t]{5}{*}{ Monitoring } & Strategic uncertainties & In-context collaboration \\
\hline & Risks & Risks adaptation and orchestration \\
\hline & Changes & $\begin{array}{l}\text { Change distilment and incremental process } \\
\text { change }\end{array}$ \\
\hline & Control framework & $\begin{array}{l}\text { Development intelligence (success metrics, } \\
\text { tracking progress) }\end{array}$ \\
\hline & Critical performance & Usage of metrics (e.g. AgileEVM) \\
\hline \multirow[t]{6}{*}{ Deliverables } & Review of performance & Practice continuous delivery \\
\hline & Financial review & $\begin{array}{l}\text { Continuous refinement toward greater } \\
\text { efficiencies }\end{array}$ \\
\hline & Quality & Improvement of the team dynamic \\
\hline & Deliverable review & Build the right thing \\
\hline & Benefits and values and review & Increase of benefits and sustainability \\
\hline & Alignment with business goals & Organizational value creation \\
\hline
\end{tabular}




\section{Project portfolio risks data analysis}

Project portfolio risk management is the systematic process of identifying, analyzing and responding to a portfolio components' risks, and includes the processes of risk management planning, identifying risks, qualitative and quantitative risk analyses, planning risk responses, and controlling risks. The aim of the quantitative risk analysis process is to analyze numerically the probability of each risk and its consequence on portfolio component objectives, as well as the extent of overall portfolio risks. This process uses simulation techniques and decision analysis to determine the probability of achieving a specific objective, quantify the risk exposure for the portfolio component and determine the size of cost and schedule contingency reserves that may be needed. It identifies risks requiring the most attention by quantifying their relative contribution to the portfolio component risks, and identifies realistic and achievable cost, schedule, and scope targets.

The analysis input is a data and information array recognized and retrieved from the collection of projects and programs executed in ten years, from 2003 - 2013, consisted from the portfolio of 15 projects within 4 programs. These programs were business process modelling, implementation of the organizational ERP system, design and the implementation of the judicial ERP system, and business continuity management. The data collection refers to the risk factors recognized in the referent projects, and the factors of project portfolio execution with the agile and lean character. The subject of interest was the probabilistic analysis based on stratified sampling of variable risks factors, which was conducted with the aim of determining the behavior of the agile structured governance processes. The analysis findings shall identify, evaluate, and provide the insight into the best concept of the process governance of the project portfolio framework. The projects' software development life cycles included traditional (prescriptive), evolutionary, agile, and tailored process models. The quantitative analysis includes the quantitative risks data analysis using Binominal, Poisson, and Beta-PERT distributions with probabilistic Monte Carlo simulation, aiming to determine the probability of risks occurrence, risks occurrence in observed period, the deviation from the most probable distribution of project costs and schedule, and in determining the relations between variables by applying the regression and sensitivity analyses. The specified distributions have been chosen as mostly applied in the domain of project management, based on literature research ${ }^{2}$. As an important result, the variables with the highest impact on governance processes are determined, constituting the input for the risk optimization process and development of the risk corrective measures, and defining the behavior of the agile structured governance processes.

\subsection{Probability analysis model development}

The probabilistic analysis can be applied to the systems with a large number of possible events, expressing the probability of a given number of events occurring in a fixed interval of time if the events occur with a known average rate and independently of the time since the last event, providing a certain spread. Given the average rate for a period of observation (uncertainties/risks and changes during the portfolio component life-cycle), and assuming that these factors impacting the processes or mix of processes producing the event flow are essentially random, the analysis shall specify how likely the occurrence of risk factors is during the period of observation, predicting the degree of spread around a known average rate of occurrence.

The starting point of the project representatives' stratification was project risk registers, as the basis for assessment of a total projects' risk reserves and development the elements for probabilistic analysis. The project risk registers were well developed, since all these projects were finished, and closed. Each of the risks falls under one of the risk categories and being structured in order to denote risks' earliest/latest occurrence, likelihood, impact, probability

\footnotetext{
${ }^{2}$ Goodpasture, J.: Project Management the Agile Way, pp. 5-10, J. Ross Publishing, USA, (2010); Project Management Institute - PMI ${ }$, The Standard for Portfolio Management Fourth Ed., Newton Square, Pennsylvania, US, (2017)
} 
factor, and its score (Probability x Impact/100), including the risk response strategy. In addition, project schedules and costs (budgets) were also developed with projects' completion dates, which provide assurance of their confidence level.

The stratification of project representatives was done based on their development life cycle, and risk assessment matrix was created per stratified data. Fig.2. depicts the assessment of the project portfolio risks. In order to prioritize the project portfolio risk factors that have the highest impact on processes and to choose the right ones for further measurements, the Lean Six Sigma Cause \& Effect Matrix (CEM) ${ }^{3}$ method was used to link the project portfolio risk factors critical to quality aspects of considered projects to the causes and effects of a problem that have been identified (see Fig.2.).

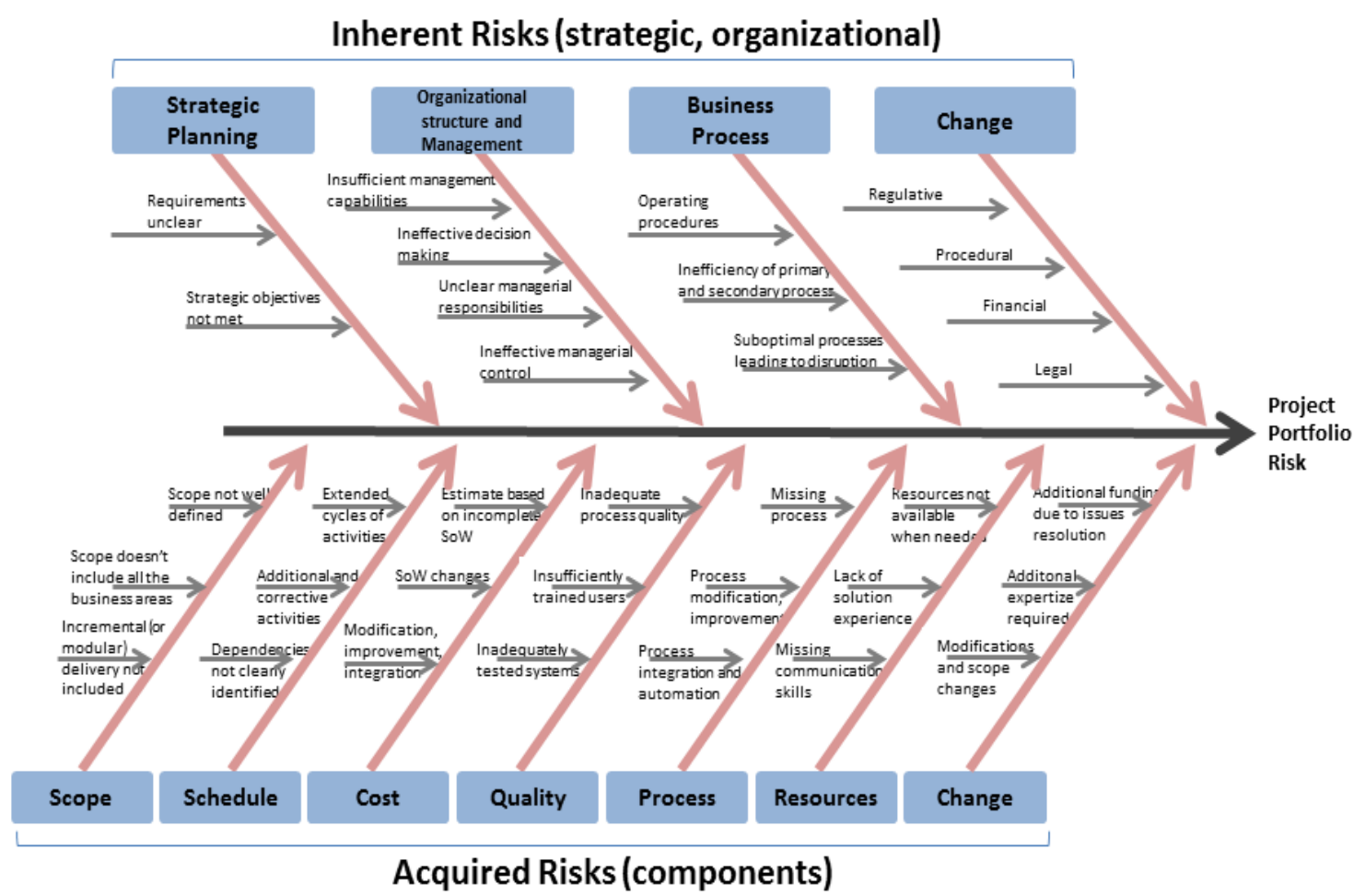

Fig. 2. Assessed project portfolio risks as per components' RBS’s

The process outputs, or conjoint factors affected the governance processes, were ranked \#1-\#12 as follows: management support and commitment to the project; accurate change management process; consistent operating procedures implemented; fit to business strategy; availability of resources during the project; proper planning; efficient communication between the project team and senior management; sufficient in-house knowledge in order to setup contingency for regular system operations; effective and efficient requirements description and approval; improvement in data quality (management reporting and financial accuracy); End-User acceptance of the optimized process flow; and data integrity. Risks having the highest impact on process outputs are shown in Table 2. If the portfolio output goal is to reduce portfolio risks, then the risks shown in Table 2. shall be managed at the first place.

Generalization of this model could be made by (a) assessing the impact of changing the output variable spread - schedule and cost/budget dependent variables from each uncertain risk variable into a probability distribution; (b) assessing a probability that each risk could occur more than once per observed interval, modelled by Binominal distribution; (c) counting the random arrival or risks occurrences per period and assessing the impact if mitigation measures

\footnotetext{
${ }^{3}$ In Lean Six Sigma, the cause and effect matrix (XY Matrix) is a tool to help quantify the relationship of several X's to several Y's, where X's are derived from the cause and effect diagram as input variables, and Y's should be the primary and secondary metrics or output measures. The CEM matrix functions on the premise of the $Y=f(x)$ equation
} 
could be developed for certain risks, modelled by Poisson distribution; and (d) assessing a distribution of risk probability factors and sampled actual impact on individual risks with regard the project costs and schedule, modelled by Beta-PERT distribution.

Table 2. Ten most significant portfolio risks

\begin{tabular}{|c|l|}
\hline$\#$ & Portfolio Risks \\
\hline 1 & Communication between key stakeholders \\
\hline 2 & Communication barriers \\
\hline 3 & Additional resources due to scope changes \\
\hline 4 & Decision making \\
\hline 5 & Stakeholders' expectations on adjustments \\
\hline 6 & Continuous processes change \\
\hline 7 & Consultants' lack of experience \\
\hline 8 & Missing and not functioning processes \\
\hline 9 & Process “gaps” in blueprint/functional document \\
\hline 10 & Organizational readiness to use systems \\
\hline
\end{tabular}

The questions to be answered by the simulations are:

"What is the probability that risks will occur more than once during the project?"

"What is the relative standing of a particular risk within a data set?"

"Which risks contribute significantly towards exceeding the project costs and running behind schedule?"

"What corrective measures can be developed for certain risks within the project portfolio?

The analysis of the case study evidence is performed in Palisade @RISK ver. 5.5 risk analysis and simulation software ${ }^{4}$, which uses a quantitative method that determine the outcomes of a decision situation as a probability distribution.

\subsection{Risk model analysis}

The project portfolio component representative used in the analysis was SAP PS project. The project's process model was evolutionary, driven by the traditional SAP ASAP method. This project was chosen for the cost and schedule analysis since if the risks were refined during the proof-of-concept, scoping and fit/gap/impact analysis accordingly, then there would be no such a budget overrun and project would not run significantly behind schedule.

Initial budget estimation was done based on rough estimate without knowing the full scope of the change, as shown in Table 3. The total project expenditure was €411.385,52 vs planned budget of $€ 260.000,00$, resulting in $63 \%$ overrun.

Table 3. Project budget

\begin{tabular}{|c|c|c|}
\hline Project budget & Planned (€) & Actual $(€)$ \\
\hline SAP PS (Budget system restructure) & $162.500,00$ & $162.500,00$ \\
\hline Change request implementation & $97.500,00$ & $100.412,54$ \\
\hline Reallocated funds from frozen projects (I) & 0 & $63.538,51$ \\
\hline Reallocated funds from frozen projects (II) & 0 & $39.160,04$ \\
\hline Final invoice & & $45.774,43$ \\
\hline Total & $260.000,00$ & $411.385,52$ \\
\hline
\end{tabular}

\footnotetext{
${ }^{4}$ Palisade Corporation, USA, http://www.palisade.com
} 
The project schedule, presented in Table 4., shows the magnitude of variation to the original schedule baseline ( 24 weeks planned vs. 64 weeks actual). Causes of such a schedule variance were in major changes caused by the clarification of the project scope, decision making process on determining the most appropriate solution between the three proposed, late involvement of the functional organization, complexity of the data conversion process, duration of the acceptance and integration tests, validation of the solution, and knowledge transfer to the organization.

Table 4. Project schedule

\begin{tabular}{|l|c|c|c|c|c|c|}
\hline Project Stages & $\begin{array}{c}\text { Planned } \\
\text { Start }\end{array}$ & $\begin{array}{c}\text { Planned } \\
\text { Finish }\end{array}$ & Weeks & $\begin{array}{c}\text { Actual } \\
\text { Start }\end{array}$ & $\begin{array}{c}\text { Actual } \\
\text { Finish }\end{array}$ & Weeks \\
\hline Project preparation & Jan/2006 & Jan/2006 & 2 & Mar/2006 & Mar/2006 & 2 \\
\hline Blueprint/Impact analysis & Jan/2006 & Feb/2006 & 6 & Mar/2006 & Jul/2006 & 20 \\
\hline Realization & Mar/2006 & Apr/2006 & 8 & Aug/2006 & Feb/2007 & 28 \\
\hline Final preparation & May/2006 & May/2006 & 4 & Mar/2007 & May/2007 & 10 \\
\hline Go live and support & June/2006 & June/2006 & 4 & June/2007 & June/2007 & 4 \\
\hline & & Total & 24 & & & 64 \\
\hline
\end{tabular}

The assumption of the Binomial distribution is that there is only one outcome for each trial, that each trial has the same probability of success, and that each trial is mutually exclusive ("Risk Occur?" or "yes" or "no" in the scenario). The simulation was configured in order its setup of distributions return random values by using Monte Carlo sampling in 1000 iterations, enabling convergence testing on all outputs, with convergence tolerance of $3 \%$ and confidence level of $95 \%$. For each significant input distribution in a scenario, the three measurements were calculated: actual median of samples in iterations meeting target; percentile median of samples in iterations meeting target; and ratio of median to original standard deviation. The larger the magnitude of this ratio, the more significant the variable is in reaching the defined target.

The scenario analysis shows all inputs (nine out of ten risks) which were significant in meeting the output target $H_{a}$ : Portfolio risk occurs $=$ True. It also shows that more than $75 \%$ of risks fall in a group of observations better than $75^{\text {th }}$ and $90^{\text {th }}$ percentile rank, meaning that more than 75 percent of risks made $H_{a}$ rank, or within these percentiles more than $75 \%$ of the observations could be found.

The sensitivity analysis, identifying significant inputs, carried out with two different analytical techniques - regression analysis and rank correlation calculation. The results of a sensitivity analysis show the sensitivity of the output variable to the input distributions, identifying the most critical inputs in the model, as shown in the Table 5.

Table 5. Risk sensitivity analysis

\begin{tabular}{|l|l|c|c|}
\hline Rank & Risk name & $\begin{array}{l}\text { Total Risk Occur? } \\
\text { Regression coeff. } \\
\text { R-Squared=1 }\end{array}$ & $\begin{array}{l}\text { Total Risk Occur? } \\
\text { Correlation coeff. } \\
\text { (Spearman Rank) }\end{array}$ \\
\hline$\# 1$ & Decision Making & 0.349 & 0.302 \\
\hline$\# 2$ & Expectations on Adjustments & 0.341 & 0.298 \\
\hline$\# 3$ & Gaps in Blueprint/Functional document & 0.337 & 0.344 \\
\hline$\# 4$ & Consultants Lack of Experience & 0.334 & 0.300 \\
\hline$\# 5$ & Additional Resources & 0.327 & 0.318 \\
\hline$\# 6$ & Continuous Process Change & 0.326 & 0.279 \\
\hline$\# 7$ & Communication Barriers & 0.324 & 0.350 \\
\hline$\# 8$ & Communication between Stakeholders & 0.302 & 0.246 \\
\hline$\# 9$ & Organizational Readiness & 0.271 & 0.275 \\
\hline$\# 10$ & Missing Processes & 0.270 & 0.297 \\
\hline
\end{tabular}


Assessing a probability of the number of discrete occurrences over a defined interval was modeled with a Poisson distribution. Assuming that the processes (risks occurrence) are essentially random, the Poisson distribution determines how likely is that risks could occur more than once per observed interval. In average, there were 4,2 risk occurrences per project stage (the project was composed of 5 stages with 21 registered risks in total). The model goal was to find the probability that the project will have at most 3 reported risks per project stage (or at most 15-reported risk per whole project) if mitigation measures were developed for project risks, so the impact is reduced if these risks occur, or probabilities of risks are reduced.

$$
f(x)=\frac{\lambda^{x} * e^{-\lambda}}{x !} \quad \text { where: } \begin{aligned}
f(x)= & \text { Poisson distribution formula for } \\
& \text { calculating probabilities } \\
\lambda= & \text { Mean number of successes in a } \\
& \text { given time period } \\
x= & \text { Number of successes required } \\
e= & \text { Base of the natural logarithmic } \\
& \text { function ln }(\sim 2.71828)
\end{aligned}
$$

Average risk occurrence per project stage:

The number of risks per project stage:

Expected result:

$P$ (at most 3 risks)

$$
\begin{aligned}
& \lambda=4.2 \\
& x \leq 3 \\
& P(x \leq 3)
\end{aligned}
$$

$$
\begin{aligned}
& =\mathrm{P}(0 \text { risks, } 1 \text { risk, } 2 \text { risks, } 3 \text { risks }) \\
& =f(0)+f(1)+f(2)+f(3) \\
& =\frac{4.2^{0} * e^{-4.2}}{0 !}+\frac{4.2^{1} * e^{-4.2}}{1 !}+\frac{4.2^{2} * e^{-4.2}}{2 !}+\frac{4.2^{3} * e^{-4.2}}{3 !} \\
& =0.0150+0.0630+0.1323+0.1852=0.3955
\end{aligned}
$$

The probability that the project will have the expectation of at most 3 reported risks per project stage if mitigation measures were developed for project risks, is 0.3955 or $40 \%$. This probability level indicates that if development of such measures is undertaken, and if these measures are applied to all the components within the portfolio, the total portfolio risks can be reduced at least $30 \%$ (up to total 15 risks occurrences with risk reduction measures developed vs. 21 reported project risks without risk mitigation being done for the case project), which complies with the portfolio output goal set to reduce portfolio risks.

Beta-PERT distribution was used in assessing of probabilities on individual risks with regard the project costs and schedule. The objective of this risks model was to find those input risk variables whose subset, or conditional median, differs significantly from the overall median, and marking them as significant in meeting the output target $H_{a}$ : Actual Cost Impact $\geq 90^{\text {th }}$ percentile rank. The analysis shows inputs (six out of ten risks) which were significant in meeting the output target $H_{a}$ : Actual Cost Impact $\geq 90^{\text {th }}$ percentile rank. More than $50 \%$ of risks could be found in a group of observations better than $75^{\text {th }}$ and $90^{\text {th }}$ percentile rank, meaning that more than 50 percent of risks made $H_{a}$ rank. The significant risk variables affecting the output (project costs) are shown in regression analysis, as represented in Fig.3. The values on $\mathrm{Y}$-axis represent the most significant input variables, and the values on $\mathrm{X}$-axis representing the amount of change in the output due to a +1 -standard deviation change in each input.

The project schedule distribution was built on risk variables with specified minimum (optimistic), most likely, and maximum (pessimistic) values of the probability factors planned vs. actual weeks. More than $80 \%$ of project stages within observed outcomes could be found in a group of observations better than $75^{\text {th }}$ and $90^{\text {th }}$ percentile rank, meaning that more than 80 percent of risks within observations made $\mathrm{H}_{\mathrm{a}}$ rank. The results, showed in Table 6., demonstrate on strong relationship between risks and project schedule. 


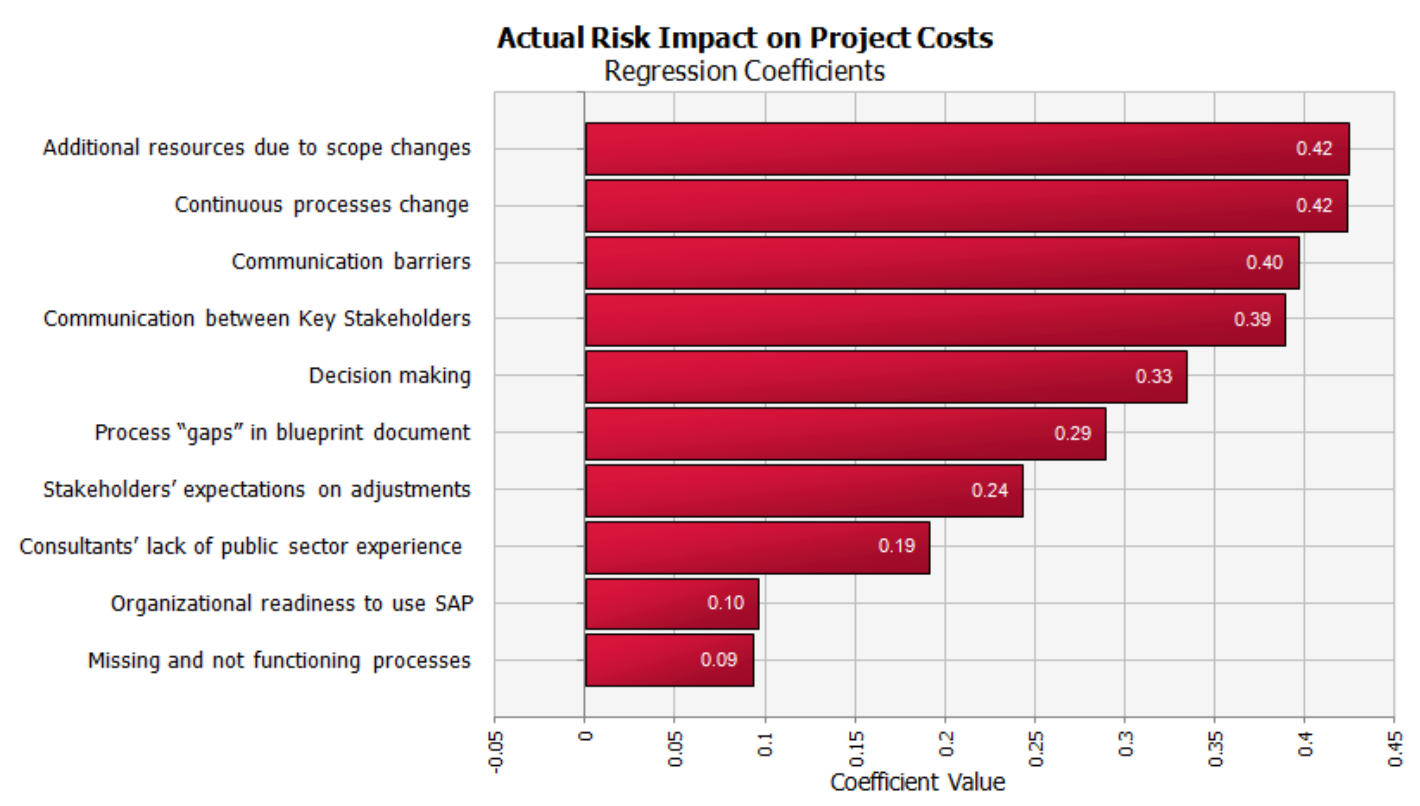

Fig. 3. Key risk inputs affecting project costs

The correlation and dependence between the schedule independent and dependent variables, quantified by Spearman's rank correlation coefficient, shows the strength of association between the two-paired sets of data, and statistical relationship.

Table 6. Schedule Sensitivity Analysis

\begin{tabular}{|l|l|l|l|}
\hline $\begin{array}{l}\text { Rank for } \\
\text { Total } \\
\text { Actual } \\
\text { Weeks }\end{array}$ & Project Stage & $\begin{array}{l}\text { Total Actual Weeks } \\
\text { Regression coeff. } \\
\text { R-Squared=1 }\end{array}$ & $\begin{array}{l}\text { Total Actual Weeks } \\
\text { Correlation coeff. } \\
\text { (Spearman Rank - } \\
\mathbf{r}_{\mathbf{s}} \text { ) }\end{array}$ \\
\hline$\# 1$ & Realization & 0.757 & 0.709 \\
\hline$\# 2$ & BBP - Impact analysis & 0.528 & 0.475 \\
\hline$\# 3$ & Final Preparation & 0.274 & 0.217 \\
\hline$\# 4$ & Project Preparation & 0.273 & 0.238 \\
\hline$\# 5$ & Go live and Support & 0.263 & 0.242 \\
\hline
\end{tabular}

The reported absolute value of $\mathrm{r}_{\mathrm{s}}{ }^{5}$ shows the strong positive correlation between the input and output variables for the Realization stage, moderate positive correlation for the BBP-Impact analysis stage, and weak positive correlation for the stages \#3-\#5 from the Table 6 . The testing of the level of statistical significance $\left(\mathrm{H}_{0}\right.$ testing of independence between variables) was done by Kendall's Tau-b rank correlation, which showed that the correlation is significant at the 0.01 level (2-tailed). Therefore, we can conclude that there is very strong evidence to believe $\mathrm{H}_{1}$, i.e. that the risks and the actual schedule values are correlated.

\subsection{Analysis results}

The risk analysis presented the sufficient evidence to answer the questions:

"What is the probability that risks will occur more than once during the project?" The scenario analysis using Binomial distribution determined all inputs (nine out of ten risks) which

\footnotetext{
${ }^{5}$ Spearman's correlation, www.statstutor.ac.uk/resources/uploaded/spearmans.pdf - the absolute guide for value or rs: .00-.19 - "very weak"; .20-.39 - "weak"; .40-.59 - "moderate”; .60-.79 - "strong”; .80-1.0 - "very strong”
} 
were significant in meeting the output target $H_{a}$ : Portfolio risk occurs $=$ True. There is a range of probability from 53,5\% - 62\%,5 that risks will occur more than once during the project.

"What is the relative standing of a particular risk within a data set?" The relative standing of a particular risk show that a decision making is the most significant risk, followed by stakeholders' expectations on adjustments, process "gaps" in blueprint / functional documents. The relative standing of the risks \#4-\#10 are consultants lack of experience, additional resources due to scope changes, continuous process change, communication barriers, communication between stakeholders, organizational readiness, and missing and not functional processes.

"Which risks contribute significantly towards exceeding the project costs and running behind schedule?" The three most critical risks affecting all project stages are decision making, communication barriers, and communication between key stakeholders. There are six risks contributing significantly towards exceeding the project costs: communication between key stakeholders, process "gaps" in blueprint/functional documents, additional resources due to scope changes, continuous processes change, stakeholders' expectations on adjustments, and communication barriers. The most critical risks affecting the project schedule are decision making, stakeholders' expectations on adjustments, and process "gaps" in blueprint / functional documents.

"What corrective measures can be developed for certain risks within the project portfolio?" Corrective risk aversion measures are observed in the next section.

\subsection{Corrective risk measures}

The analysis indicated if the risk corrective measures were developed, the expectation for risk reduction is $40 \%$ for the analyzed project, and if these measures are applied to all the components within the portfolio, the total portfolio risks can be reduced at least $30 \%$.

The development of corrective risk measures involves creation of the agile risk management framework for project portfolio governance process domains enabling a progressive risk reduction. This approach requires early and continuous feedback from all involved stakeholders, and clarity about investment decisions to whom the benefits will be provided. Each portfolio iteration should focus on continuous risk assessment, with component's features reducing risk and providing maximum business value. It also involves a continuous review and constant readjustment against assumptions and changes in business environment, allowing determining component's criticality and clustering. Realistic, meaningful and adaptive metrics shall be established and reported regularly to the key stakeholders and used as an input to decision making and performance improvement. Also, a formal, repeatable post-implementation review process and benefits register shall be established to track gained benefits.

The answer on the question "What corrective measures can be developed for certain risks within the project portfolio?" is achievable through the agile and lean project portfolio governance risk management approach, where the risk management measures are integrated into the governance process domains by:

1. Adopting structured risk management processes to the governance of project portfolio in order to strengthen risk averse strategies;

2. Applying and sustaining risk management processes to a project portfolio and its components in assessing, analyzing risks, developing risk management plan, and management of risks;

3. Agile and lean practices allow integration of risk management and performance management; and

4. Agile and lightweight practices in risk and change management that make project portfolio risk reduction possible for the most critical risks:

- Organizational structure and managerial risk (decision making) by establishing a clarity about investment decisions to whom the benefits will be provided; 
- Strategic planning risks (communication barriers and communication between key stakeholders) by early and continuous feedback from all involved stakeholders, and assessment of strategic uncertainties;

- Organizational business process risks (continuous process change, missing and not functional processes, and process gaps in functional documents) by continuous risks assessment and continuous review and constant readjustment against assumptions and changes in business environment;

- Resource risk (lack of experience) by identifying and analyzing potential risks in advance and progressive risk reduction;

- Component scope risk (scope changes) by determining a portfolio component's criticality, clustering and data analysis (cost, schedule variances, quality and risks);

- Component cost and schedule risks by integrating performance management with risk management to maximize the likelihood of achieving portfolio objectives, identifying corrective actions, and applying performance measurements.

Developed corrective risk aversion measures can provide answers on the following two questions: "Can project portfolio be delivered within the planned budgets upon development of the corrective measures?" and "How much contingency should have been included for the revised budgetary levels to be achieved with a certain degree of confidence?"

The answer on the first question is yes, the project portfolio can be delivered within the planned budgets upon development of the corrective measures, based on the change control process upon finalizing each iteration where shippable work and the release backlog form a new project baseline. The adjustment in baseline correlates with the calculated release date estimates (mean velocity predictions or estimate at completion), where the fluctuations in planned vs. actual costs being reduced in the later iterations.

The answer on the second question on achieving a confident budgetary level throughout a component life cycle requires modelled contingency simulation of possible actual costs where the planned item costs are correlated with risk variables.

\section{Conclusions}

The analysis revealed that the inherent risks (organizational structure and managerial, strategic planning, business process, and change management) build majority of critical risks (60\%), while acquired risks (process "gaps" in blueprint/functional documents, consultants lack of experience, additional resources due to scope changes, missing and not functional processes) indicate business process, resources, and scope risks as an effect of continuously present inherent risks influencing and impacting the portfolio component execution.

Furthermore, findings confirm that the inherent risks (communication between key stakeholders, continuous processes change, stakeholders' expectations on adjustments, and communication barriers) constitute $\sim 70 \%$ of risks contributing significantly towards exceeding component's costs, indicating that the costs of all portfolio components will subsequently be affected. The three highest ranked risks impacting the project schedule represent the uncertainties most commonly connected with the scope issues: insufficiently defined and not clear requirements in the situation where the expectations are high, inadequate decisionmaking, and process gaps, consequently causing the scope change pressures resulting in schedule and costs overrun. If the risk corrective measures were developed and if these measures are applied to all the components within the project portfolio, the total portfolio risks can be reduced up to $40 \%$.

To conclude, the project portfolio governance framework enriched with agile and lean methods affirm the improvement of governance processes. Development of an agile and lightweight strategy for project portfolio process domains with risks reduction factors in governance of project portfolios shall decrease the implementation risks from component's inception till the review of achieved deliverables and realized benefits of a transitioned components. 


\section{References}

1. Information Systems Audit and Control Association - ISACA ${ }^{\circledR}, \mathrm{COBIT}^{\circledR} 5$ - A Business Framework for the Governance and Management of Enterprise IT, USA, (2012)

2. Project Management Institute - PMI ${ }^{\circledR}$, The Standard for Portfolio Management Third Ed., pp. 19-30. Newton Square, Pennsylvania, USA, (2013)

3. DDJ State of the IT Union Survey on the organizational project governance approach (2009), http://www.ambysoft.com/surveys/stateOfITUnion200907.html, Accessed March 20, 2013

4. Boehm, B., Turner, R.: Balancing Agility and Discipline - A Guide for the Perplexed, Addison-Wesley, Boston, MA, USA, (2004)

5. de Luna, A.J.H., Kruchten, P., do E. Pedrosa, M.L.G., de Almeida Neto, H.R., de Moura, H.P., State of the Art of Agile Governance: A systematic Review, Int'l Journal of Computer Science \& Information Technology (IJCSIT) Vol 6. No.5. October 2014

6. Cooke, J.L.: Agile Productivity Unleashed, IT Governance Publishing, UK, (2010)

7. Dinsmore, P.C. et al.: Enterprise Project Governance: A Guide to the Successful Management of Projects Across the Organization, Amacom, US, (2012)

8. Krebs, J.: Agile Portfolio Management, Microsoft Press, (2008)

9. Kaplan, R.S., Norton, D.P.: Strategy Maps: Converting Intangible Assets into Tangible Outcomes, Harvard Business School Press, (2004)

10. Lamm, J. et al.: Under Control: Governance Across the Enterprise, CA Press Apress, US, (2010)

11. Moore, S.: Strategic Project Portfolio Management - Enabling a Productive Organization, John Wiley \& Sons, Inc., Hoboken, New Jersey, USA, (2010)

12. McMahon, P.E.: Integrating CMMI and Agile Development, Addison-Wesley, Boston, MA, USA, (2011)

13. Olson, D.L., Wu, D.: Enterprise Risk Management Models, Springer-Verlag, (2010)

14. Paladino, B.: Five Principles of Corporate Performance Management, John Wiley \& Sons, (2007)

15. Parmenter, D.: Key Performance Indicators (KPI): Developing, Implementing, and Using Winning KPIs, John Wiley \& Sons, (2007)

16. Rad, P., Levin, G.: Project Portfolio Management Tools and Techniques, IIL Publishing, NY USA, (2006)

17. Simons, R.: Levers of Control: How Managers Use Innovative Control Systems to Drive Strategic Renewal, Harvard Business School Press, (1995)

18. Van Grembergen, W., De Haes, S.: Business Strategy and Applications in Enterprise IT Governance, IGI Global, US, (2012)

19. Agile Governance, http://www.agilehelpline.com/2011/03/agile-governance.html. Accessed May 20, 2013

20. Marks, E.A.: A Lean Enterprise Governance Manifesto - Improving Business Performance with Event-Driven Governance, Agile Path Corporation, Microsoft, (2012)

21. Schwaber, C.: The Changing Face of Application Life-Cycle Management, pp. 3, US, (2006)

22. Hines, P.: The Principles of the Lean Business System, pp. 1-6. Lean Enterprise Research Centre, Cardiff University, UK, (2010)

23. Hines, P., Found, P., Griffiths, G., Harrison, R.: Staying Lean - Thriving, not just surviving, pp. 4-11. Lean Enterprise Research Centre, Cardiff University, UK, (2008)

24. Dr. Hobbs, B., Dr. Miller, R.: The Strategic Front End of Large Infrastructure Projects: A Process of Nesting Governance, Proceedings of PMI Research Conference, PMI, US, (2002)

25. Klakegg, O.J., Williams, T., Magnussen, O., Glasspool, H.: Governance Frameworks for Public Project Development and Estimation, PMI, Project Management Journal, Vol 39, Supplement, S27-S42, (2008) 